\title{
Can short-term effectiveness of anti-pronation taping predict the long-term outcomes of customized foot orthoses: developing predictors to identify characteristics of patients with plantar heel pain likely to benefit from customized foot orthoses
}

Fu-Lien Wu', Yi-Fen Shih', Si-Huei Lee², Hong-Ji Luo ${ }^{1}$ and Wendy Tzyy-Jiuan Wang ${ }^{1 *}$

\begin{abstract}
Background: Foot orthoses are widely used to manage plantar heel pain (PHP). However, the evidence concerning the effect of foot orthoses on PHP is not conclusive. The study aims to identify the characteristics of patients with PHP likely to achieve a positive outcome after customized foot orthoses and to verify the concept that patients who respond positively to anti-pronation taping would achieve a positive prognosis after wearing foot orthoses for six months.

Methods: This is a prospective observational cohort study. Seventy-four patients with PHP underwent a baseline examination and received anti-pronation taping to their painful feet. The taping effects on pain and function were assessed at the 7-day follow-up visit. Then, all patients received an intervention for their PHP with customized foot orthoses for six months. Outcome was assessed with a numeric pain rating scale, the patient-specific functional scale, the foot function index, and the global rating of perceived change. Significant reduction of pain, increase of function, and perception of a meaningful improvement were considered a positive response.
\end{abstract}

Results: Of 74 patients, 49 had a positive response to the customized foot orthosis treatment. Five predictors were identified: (1) the average pain intensity decreased by over 1.5 points with taping, (2) the range of ankle plantarflexion > 54 degrees, (3) the strength of ankle plantarflexors on the symptomatic side was equal to or stronger than that on the other side, (4) the range of hip internal rotation < 39 degrees, and (5) the range of hip external rotation $>45$ degrees. The presence of three or more predictors increased the rate of achieving positive outcome from 66 to $89 \%$.

Conclusions: The predictors of customized foot orthosis outcome in patients with PHP are related to several physical measures of a lower extremity. Findings of the study can be used to screen and select patients with PHP for foot orthosis intervention. Moreover, patients who respond positively to anti-pronation taping would also benefit from the customized foot orthoses. However, since there was no control group in the current study, it is inappropriate to draw conclusions about the effectiveness of the foot orthoses treatment.

(Continued on next page)

\footnotetext{
* Correspondence: tjwang@ym.edu.tw

'Department of Physical Therapy and Assistive Technology, National Yang-Ming

University, No.155, Sec.2, Linong Street, Taipei 112, Taiwan, Republic of China

Full list of author information is available at the end of the article
}

(c) The Author(s). 2019 Open Access This article is distributed under the terms of the Creative Commons Attribution 4.0 International License (http://creativecommons.org/licenses/by/4.0/) which permits unrestricted use, distribution, and reproduction in any medium, provided you give appropriate credit to the original author(s) and the source, provide a link to the Creative Commons license, and indicate if changes were made. The Creative Commons Public Domain Dedication waiver (http://creativecommons.org/publicdomain/zero/1.0/) applies to the data made available in this article, unless otherwise stated. 
(Continued from previous page)

Trial registration: The trial was retrospectively registered with the Australian and New Zealand Clinical Trials Registry (ACTRN 12617000119392).

Keywords: Clinical decision, Prediction, Prognostic factors, Foot orthoses, Taping

\section{Background}

Plantar heel pain (PHP) is a highly prevalent foot disorder, accounting for $8-20 \%$ of both nonathletic and athletic populations [1-3]. First-step pain occurring after prolonged sitting or lying is the most disturbing symptom in patients with PHP [4]. Poor shock absorption of the plantar fascia in supporting body weight is a common contributing factor in explaining the pathomechanism of the PHP [5].

Multiple extrinsic and intrinsic predisposing factors regarding PHP have been reported, inclusive of excessive foot pronation, prolonged weight-bearing activity, limited range of ankle dorsiflexion, unfavorable environment for shock absorption, high body mass index and history of previous lower limb trauma [4, 6-9]. Excessive pronation in foot posture has been viewed as an important biomechanical finding in patients with PHP $[4,6]$. Foot orthoses are commonly used to provide a biomechanical anti-pronation support to realign a more pronated foot posture. The strain over the plantar fascia might be attenuated by reducing excessive uncontrolled foot pronation with foot orthoses, resulting in decreasing symptoms of PHP [10, 11]. Despite both customized and prefabricated foot orthoses providing positive short-term ( $<3$ months) effects in decreasing foot pain and improving function $[4,11]$, the long-term (>3 months) effects have not been well studied [12, 13]. One possible reason for the limited evidence on long-term effects of foot orthoses may be related to the heterogeneous subject populations in different studies. Not every patient with PHP benefits from foot orthoses. Hence, identifying subgroups of patients who respond positively to foot orthoses in order to improve the treatment efficacy is worth investigating.

Vicenzino et al. proposed the concept of a 'treatment direction test (TDT)' to identify patients who respond to using foot orthoses in treatment. They claimed that anti-pronation taping could be used to assess and determine the effectiveness of wearing foot orthoses [14-16]. One case report and one case series study verified this concept $[14,16]$. However, because of the small sample sizes of these two studies, solid evidence for supporting the theory that patients with PHP who are responders to anti-pronation taping would also benefit from foot orthosis intervention has not been confirmed. In order to achieve best practice intervention, it would be prudent to determine predictors associated with successful response to treatment of foot orthoses.
In the past two decades, several studies have identified clinical predictors to enhance clinical professionals' decision-making process in managing many musculoskeletal disorders, such as low back pain, patellofemoral pain syndrome and neck pain, by classifying patients into specific treatment-based subgroups [17-19]. However, the evidence with regard to predictive factors related to customized foot orthoses for treating PHP was insufficient. Therefore, this study aimed to identify the characteristics of patients with PHP likely to benefit from customized foot orthoses and to verify the concept that patients who respond positively to anti-pronation taping would also benefit from the customized foot orthoses.

\section{Methods}

\section{Subjects}

This is a prospective observational cohort study of 74 patients diagnosed with plantar heel pain by a physiatrist in a general hospital. Inclusion criteria for participants consisted of age older than 20 years, a symptom over the plantar heel or the plantar fascia area, a pain score of 3 points or high on an 11-point (0-10) numeric rating scale (NRS), and a symptom duration of at least 4 weeks. Patients were excluded when they had one of the following situations: (1) symptoms associated with the neurological system, (2) having lower extremity trauma in the past six months, (3) receiving lower extremity surgery in the past six months, or (4) had received corticosteroid injections or other interventions (including taping and foot orthoses) for PHP in the past three months. Before participating in this study, all patients signed an informed consent form that was approved by the Institutional Review Board of Taipei Veterans General Hospital (2013-01-026B). This trial was retrospectively registered with the Australian and New Zealand Clinical Trials Registry (ACTRN12617000119392).

\section{Examination}

To record stable baseline symptoms, we advised all patients to maintain but not to increase their usual activity level at least 2 weeks before the baseline examination. Both a standardized history taking and physical examination were performed on all patients by an experienced physical therapist. A numeric rating scale (NRS) was used to assess the severity of 
pain [20]. The Foot Function Index (FFI) [21] and Patient-specific Functional Scale (PSFS) [22] were used for quantification of activity limitation and functions. The FFI is a self-reported 23-item questionnaire containing three domains: disability (nine items), activity limitation (five items), and pain (nine items) for evaluating multiple foot and ankle problems [21]. The range of FFI score is between 0 and 100, with a higher score representing more severe pain, disability or functional restrictions [23]. PSFS was assessed with the method of instructing patients to describe three activities they were incapable of performing, or which were difficult to execute because of symptoms. Each patient then self-scored the easiness of each activity on a scale from 0 to 10 . Lower scores indicate more difficulty in performing the activity [22].

The passive range of motion of each lower limb joint was measured with a goniometer [24-26]. The isometric muscle strength of the lower limb was assessed with a MicroFET 2 dynamometer (Hoggan Health Industries, Inc., Draper, UT) [27, 28]. Other measurements including bony alignment and special tests $[24,29-35]$ are presented in Table 2 and Table 3. We recorded all physical examination variables on the symptomatic side (or the most affected side if both sides were involved) and the contralateral side. The between-side difference of each variable was then calculated by subtracting the value of the contralateral side from the value of the symptomatic side. The Foot Posture Index (FPI) containing six validated and observable items was used to quantify the relaxed standing foot posture [36].

\section{Intervention}

In order to determine the predictive value of the taping effect on the response from foot orthoses, all patients received customized biomechanical antipronation taping (BAPT) before wearing the foot orthoses. BAPT was applied with rigid adhesive tapes $(3.8 \mathrm{~cm}$ Leuko Sports Tape, Beiersdorf Australasia Ltd., North Ryde, Australia) by a physical therapist. The BAPT method consisting of two taping components, the arch taping and the calcaneal taping, is depicted in Fig. 1 [32, 37, 38]. Each patient was instructed to keep the tape on for 2 to 3 days. All patients were advised to continue their usual activities without exacerbating their symptoms and to avoid pain medications prior to the follow-up visit which was arranged 1 week later.

At the follow-up visit for taping effect, patients reported the changes over the period of BAPT treatment by completing the NRS for pain, FFI, PSFS and the global rating of change (GROC) scale. The GROC scale is a self-administered measure which can be utilized to evaluate the individual's perception of change after a treatment $[39,40]$. Range of the GROC is from +7 (greatest improvement) to zero (no change) to -7 (greatest deterioration). The score of GROC $\geq+4$ has been viewed as the cutoff point of a considerable improvement following an intervention [39].

After being assessed for the effectiveness of BAPT, all patients received an individualized foot orthosis intervention for six months. A pair of heat-moldable customized foot orthoses (Vasyli Custom Orthotics; Vasyli International, Labrador, Australia) was given to each patient. All patients were instructed to maintain their usual activities within the limits of symptoms and to wear the foot orthoses for as much time as possible in their day-to-day activities. Subjects were asked to return for follow-up six months later. The response of the foot orthoses was evaluated with the NRS for pain, PSFS, FFI for function, and the GROC scale for perceived effect at the 6-month follow-up visit. The assessor and treatment provider was the same physical therapist.

\section{Determination of treatment success}

At the 6-month follow-up visit, patients would be classified into either the success or nonsuccess group based on their reported outcomes. The criteria for inclusion of the success group were: (1) reducing the pain intensity by more than two points [20] or more than $50 \%,(2)$ decreasing the FFI score by more than seven points or improving the FFI or PSFS score by more than 50\% [23], and (3) reporting an overall change on the GROC scale of +4 or higher [39]. All patients in the success group had to meet all three criteria.

\section{Data analysis}

According to the rule of thumb recommended by Peduzzi et al. [41] and Harrell et al. [42], 10 outcome events were required for each predictor variable that was entered into a multiple logistic regression. The sample size for this study was estimated to include seven to eight potential predictors in the final regression model, therefore, we aimed to recruit 70 to 80 patients with PHP.

We used SPSS version 20.0 (IBM Corp., Armonk, NY, USA) to determine whether any potential predictor variables and anti-pronation taping response identified patients who benefited from the 6-month foot orthosis treatment. Firstly, univariate analyses including independent $t$ tests for continuous variables and chi-square tests for categorical variables were used to determine the significant differences of independent variables between the success and the nonsuccess groups. The method to derive the optimal 

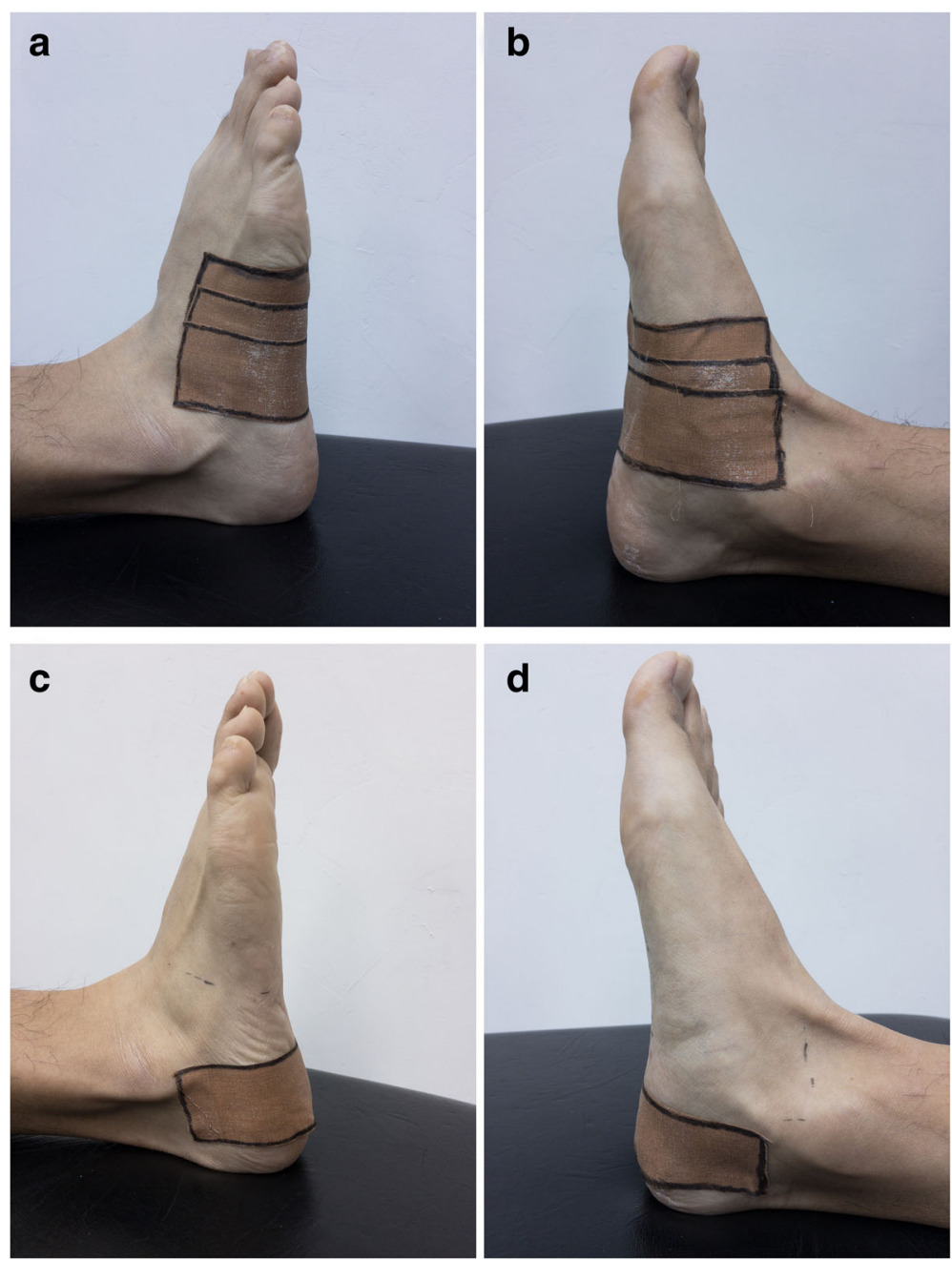

Fig. 1 Biomechanical anti-pronation taping includes 2 elements, arch taping and calcaneal taping. (a) Arch taping, lateral view. (b) Arch taping, medial view. (c) Calcaneal taping, lateral view. (d) Calcaneal taping, medial view

cutoff point of each significant continuous variable in the independent $\mathrm{t}$ test was the Receiver Operating Characteristic (ROC) curve. Then the variables that demonstrated significant between-group differences at $p<0.15$ were entered into a multiple logistic regression to derive significant predictors for a positive outcome from the use of customized foot orthoses. A significance level of 0.05 was used for this multiple logistic regression.

\section{Results}

Seventy-five patients with PHP participated in this study from March 2013 to June 2016. One patient dropped out from the study due to the incapability of returning for the first-week follow-up. The average age of all subjects was $48.4 \pm 14.5$ years. The process of recruiting and retaining subjects is shown in Fig. 2 .
According to the criteria of judging the positive outcome, 49 patients (66\%) were classified into the success group and 25 patients (34\%) into the nonsuccess group. Table 1 provides the baseline data of patients with successful and unsuccessful outcomes. The selfreported measures and the physical examination variables for the study participants are presented in Tables 2, 3, 4 to 5 .

Eight potential demographic, self-reported and physical examination variables which demonstrated significant between-group differences in the univariate analyses were retained as prediction variables. The accuracy statistics and 95\% confidence intervals (CIs) for all eight potential predictors entering into the logistic regression are presented in Table 6. The final multiple logistic regression identified five predictors (Table 7) including the average pain intensity 


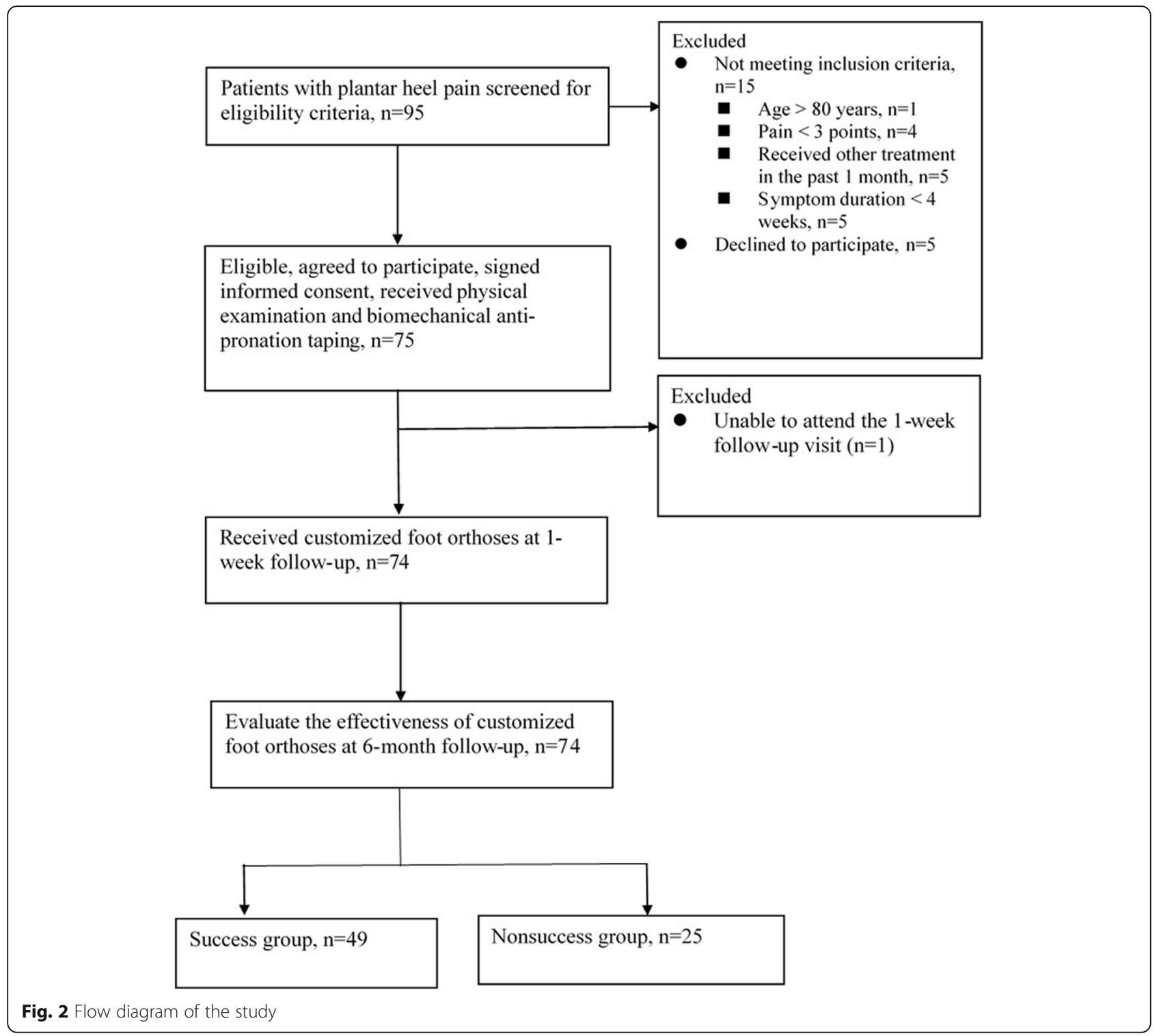

decreased by over 1.5 points after taping, the range of ankle plantarflexion $>54$ degrees, the strength of ankle plantarflexors on the symptomatic side was equal to or stronger than that on the contralateral side, the range of hip internal rotation $<39$ degrees, and the range of hip external rotation $>45$ degrees (Hosmer-Lemeshow chi-square $=8.9, \mathrm{df}=8, p=0.347$, Nagelkerke $\mathrm{R}$ square $=0.511$ ).

The pre-test rate of success with 6-month foot orthosis intervention was $66 \%$. Considering the current clinical predictors, if the patient exhibited at least three predictors, the positive likelihood ratio (+LR) was 4.3 (95\% CI: 1.9, 9.5) with an 89\% (95\% CI: 79, 99\%) post-test rate of success (Table 8). If a patient exhibited fewer than three criteria of this prediction model, the post-test rate of success would be below $80 \%$.

\section{Discussion}

This study develops a clinical prediction rule that identified several clinically measurable characteristics to predict a positive prognosis after a 6-month foot orthosis intervention for patients with PHP. The rate of success could increase from 66 to $89 \%$ with a + LR of 4.3 if a patient exhibited three of the following five predictors: (1) the average pain intensity decreased by over 1.5 points after BAPT, (2) the range of ankle plantarflexion $>54$ degrees, (3) the strength of ankle plantarflexors on the symptomatic side was equal to or stronger than that on the contralateral side, (4) the 
Table 1 Baseline demographic data

\begin{tabular}{|c|c|c|c|c|}
\hline Variable & All Subjects $(n=74)$ & Success $(n=49)$ & Nonsuccess $(n=25)$ & $p$ value \\
\hline Age, year & $48.4 \pm 14.5$ & $49.0 \pm 14.1$ & $47.2 \pm 14.6$ & 0.630 \\
\hline Women, n (\%) & $57(77.0 \%)$ & $38(77.6 \%)$ & $19(76.0 \%)$ & 1.000 \\
\hline Body mass index, $\mathrm{kg} / \mathrm{m}^{2}$ & $23.8 \pm 3.7$ & $24.1 \pm 3.6$ & $23.4 \pm 4.0$ & 0.453 \\
\hline Duration of symptom, month & $30.3 \pm 55.7$ & $29.3 \pm 45.1$ & $32.1 \pm 73.4$ & 0.839 \\
\hline First-step pain NRS & $4.6 \pm 2.7$ & $4.7 \pm 2.7$ & $4.3 \pm 2.8$ & 0.599 \\
\hline Usual pain NRS & $4.9 \pm 1.8$ & $5.1 \pm 1.7$ & $4.4 \pm 1.9$ & $0.122^{*}$ \\
\hline PSFS & $4.6 \pm 1.5$ & $4.6 \pm 1.5$ & $4.5 \pm 1.6$ & 0.810 \\
\hline $\mathrm{FFI}$ & $34.3 \pm 17.6$ & $35.2 \pm 16.2$ & $32.5 \pm 20.3$ & 0.533 \\
\hline Weekly working time, hour & $32.7 \pm 22.4$ & $32.7 \pm 23.0$ & $32.8 \pm 21.6$ & 0.992 \\
\hline Daily weight-bearing time, hour & $3.1 \pm 2.9$ & $3.0 \pm 2.6$ & $3.3 \pm 3.3$ & 0.672 \\
\hline Dominant leg: right, $n$ (\%) & 67 (90.5\%) & $43(87.8 \%)$ & $24(96.0 \%)$ & 0.411 \\
\hline Mode of onset: gradual, $n$ (\%) & $48(64.9 \%)$ & $30(61.2 \%)$ & $18(72.0 \%)$ & 0.567 \\
\hline Episode: first, $n$ (\%) & $44(59.5 \%)$ & $29(59.2 \%)$ & $15(60.0 \%)$ & 1.000 \\
\hline
\end{tabular}

*p $<0.15$

NRS numeric rating scale, PSFS patient-specific functional scale, FFI foot function index

Data present as mean \pm SD for continuous variables and percent for categorical variables

range of hip internal rotation $<39$ degrees, and (5) the range of hip external rotation $>45$ degrees.

The first predictive factor emerged from the final logistic regression model was that the average pain intensity decreased by over 1.5 points with taping. Based on this result, we verified that patients who respond positively to anti-pronation taping would also benefit from the customized foot orthoses. The decrease in pain with taping can be partly attributed to the reduction of excessive foot pronation during walking. Excessive or prolonged foot pronation during the stance phase of gait has been recognized as a risk factor of developing PHP $[4,6,9]$. One meta-analysis revealed that both anti-pronation taping and foot orthoses significantly decreased the calcaneus eversion angle during standing or walking, thereby causing reduction of foot pronation [10]. Because anti-pronation taping and foot orthoses provide a biomechanical anti-pronation support on the foot to decrease the excessive stress over the plantar fascia, patients with

Table 2 Baseline measurement of the foot and ankle joint

\begin{tabular}{|c|c|c|c|c|}
\hline Variable & All Subjects $(n=74)$ & Success $(n=49)$ & Nonsuccess $(n=25)$ & $p$ value \\
\hline Rearfoot varus in STNP, deg & $7.3 \pm 2.5$ & $7.0 \pm 2.3$ & $7.8 \pm 2.7$ & 0.227 \\
\hline Forefoot varus in STNP, deg & $10.2 \pm 4.2$ & $10.7 \pm 3.2$ & $9.2 \pm 5.7$ & $0.141^{*}$ \\
\hline Rearfoot inversion ROM, deg & $21.8 \pm 6.1$ & $21.5 \pm 7.3$ & $20.9 \pm 5.6$ & 0.649 \\
\hline Rearfoot eversion ROM, deg & $9.3 \pm 4.8$ & $9.1 \pm 5.1$ & $9.5 \pm 4.2$ & 0.733 \\
\hline 1st MTP joint extension ROM, deg & $69.3 \pm 11.5$ & $68.7 \pm 10.2$ & $70.6 \pm 13.9$ & 0.505 \\
\hline Ankle dorsiflexion ROM, deg & $10.8 \pm 7.1$ & $10.5 \pm 7.1$ & $11.6 \pm 7.1$ & 0.536 \\
\hline Ankle plantarflexion ROM, deg & $53.1 \pm 12.1$ & $54.7 \pm 11.0$ & $50.1 \pm 13.7$ & $0.122^{*}$ \\
\hline Navicular drop test, ${ }^{34} \mathrm{~mm}$ & $10.9 \pm 4.6$ & $11.0 \pm 4.6$ & $10.8 \pm 4.7$ & 0.893 \\
\hline Calcaneus valgus in $\mathrm{RCSP}_{1}^{35}$ deg & $6.0 \pm 5.0$ & $6.1 \pm 5.0$ & $5.9 \pm 5.2$ & 0.867 \\
\hline Calcaneus valgus in NCSP, ${ }^{35}$ deg & $-4.7 \pm 3.5$ & $-4.9 \pm 3.2$ & $-4.2 \pm 4.1$ & 0.437 \\
\hline Foot posture index & $6.3 \pm 3.7$ & $6.2 \pm 3.8$ & $6.5 \pm 3.5$ & 0.715 \\
\hline
\end{tabular}

${ }^{*} p<0.15$

STNP Subtalar joint neutral position, ROM Range of motion, MTP Metatarsophalangeal, RCSP Relaxed calcaneal stance position, NCSP Neutral calcaneal stance position

Data present as mean \pm SD 
Table 3 Baseline measurement of the hip and knee joints

\begin{tabular}{lllll}
\hline Variable & All Subjects $(n=74)$ & Success $(n=49)$ & Nonsuccess $(n=25)$ & $p$ value \\
\hline Femoral neck anteversion, ${ }^{27}$ deg. & $7.7 \pm 5.8$ & $7.5 \pm 6.3$ & $8.0 \pm 4.5$ & $17.7 \pm 6.9$ \\
Tibial lateral torsion, ${ }^{32} \mathrm{deg}$ & $17.9 \pm 7.0$ & $18.1 \pm 7.2$ & $1.1 \pm 7.8$ & 0.825 \\
Leg length difference, $^{35} \mathrm{~mm}$ & $1.0 \pm 6.5$ & $1.0 \pm 5.8$ & $13.6 \pm 7.0$ & 0.716 \\
Quadriceps angle, $^{34} \mathrm{deg}$ & $14.3 \pm 5.7$ & $14.7 \pm 4.9$ & $40.4 \pm 13.4$ & 0.452 \\
Hip internal rotation ROM, deg & $35.8 \pm 13.1$ & $33.5 \pm 12.4$ & $43.3 \pm 12.3$ & $0.030^{*}$ \\
Hip external rotation ROM, deg & $47.2 \pm 12.8$ & $49.2 \pm 12.7$ & $62.2 \pm 14.4$ & $0.060^{*}$ \\
Straight leg raise range, ${ }^{36}$ deg & $58.9 \pm 14.1$ & $57.2 \pm 13.8$ & $-18.6 \pm 9.8$ & 0.157 \\
Hip flexion ROM in Thomas test, ${ }^{37}$ deg & $-19.2 \pm 9.5$ & $-19.5 \pm 9.4$ & $50.0 \pm 15.7$ & 0.718 \\
Knee flexion ROM in Thomas test, ${ }^{37} \mathrm{deg}$ & $50.0 \pm 14.5$ & $50.0 \pm 14.0$ & $16.4 \pm 6.7$ & 0.999 \\
Hip adduction ROM in Ober's test, ${ }^{38} \mathrm{deg}$ & $14.5 \pm 9.2$ & $13.6 \pm 10.1$ & 0.221
\end{tabular}

${ }^{*} p<0.15$

ROM Range of motion

Data present as mean \pm SD

PHP who received either the taping or orthosis intervention should show similar positive responses. Our study results supported the concept of 'treatment direction test (TDT)' introduced by Vicenzino et al. [14-16]. The TDT involves using anti-pronation taping to determine if controlling excessive foot pronation would result in a reduction of patients' pain and discomfort during their physical activity. If a TDT was positive, i.e. the patient showed improvement in pain after receiving anti-pronation taping, we would assume that the patient would benefit from the foot orthoses. From the results of our study, a

Table 4 Baseline isometric muscle strength normalized with body weight (\%)

\begin{tabular}{|c|c|c|c|c|}
\hline Variable & All Subjects $(n=74)$ & Success $(n=49)$ & Nonsuccess $(n=25)$ & $p$ value \\
\hline Ankle dorsiflexor & $26.4 \pm 7.4$ & $25.8 \pm 6.7$ & $27.5 \pm 8.7$ & 0.356 \\
\hline Ankle dorsiflexor (between-side difference) & $0.1 \pm 3.7$ & $0.1 \pm 3.6$ & $0.1 \pm 3.8$ & 0.956 \\
\hline Ankle plantarflexor & $34.9 \pm 13.0$ & $35.0 \pm 13.0$ & $35.0 \pm 13.3$ & 0.814 \\
\hline Ankle plantarflexor (between-side difference) & $-0.3 \pm 5.3$ & $0.8 \pm 5.2$ & $-2.4 \pm 4.8$ & $0.011^{*}$ \\
\hline Ankle invertor & $14.9 \pm 5.9$ & $14.5 \pm 5.7$ & $15.7 \pm 6.4$ & 0.420 \\
\hline Ankle invertor (between-side difference) & $-0.5 \pm 3.4$ & $-0.6 \pm 3.4$ & $-0.4 \pm 3.6$ & 0.857 \\
\hline Ankle evertor & $15.1 \pm 6.3$ & $14.7 \pm 6.1$ & $15.9 \pm 6.8$ & 0.444 \\
\hline Ankle evertor (between-side difference) & $-0.7 \pm 11.2$ & $0.7 \pm 2.9$ & $-3.4 \pm 18.8$ & 0.296 \\
\hline 1st toe flexor & $8.7 \pm 2.9$ & $-0.5 \pm 9.4$ & $4.8 \pm 9.2$ & 0.896 \\
\hline 1st toe flexor (between-side difference) & $-0.2 \pm 1.6$ & $8.7 \pm 3.0$ & $8.8 \pm 2.8$ & 0.714 \\
\hline Knee flexor & $15.9 \pm 4.8$ & $16.3 \pm 4.4$ & $15.2 \pm 4.9$ & 0.357 \\
\hline Knee flexor (between-side difference) & $-0.3 \pm 1.5$ & $-0.3 \pm 1.6$ & $-0.2 \pm 1.2$ & 0.634 \\
\hline Knee extensor & $25.5 \pm 10.1$ & $26.5 \pm 11.3$ & $23.7 \pm 7.0$ & 0.200 \\
\hline Knee extensor (between-side difference) & $2.2 \pm 7.3$ & $2.1 \pm 8.9$ & $2.3 \pm 2.0$ & 0.874 \\
\hline Hip flexor & $35.3 \pm 7.1$ & $22.0 \pm 5.9$ & $21.2 \pm 5.9$ & 0.585 \\
\hline Hip flexor (between-side difference) & $0.4 \pm 2.9$ & $0.7 \pm 3.1$ & $-0.0 \pm 2.4$ & 0.348 \\
\hline Hip extensor & $25.9 \pm 8.3$ & $25.6 \pm 8.1$ & $26.5 \pm 8.7$ & 0.643 \\
\hline Hip extensor (between-side difference) & $0.6 \pm 2.4$ & $0.5 \pm 2.6$ & $0.8 \pm 1.9$ & 0.598 \\
\hline Hip abductor & $19.3 \pm 4.1$ & $18.9 \pm 3.9$ & $20.0 \pm 4.4$ & 0.289 \\
\hline Hip abductor (between-side difference) & $-0.1 \pm 2.7$ & $-0.3 \pm 2.7$ & $0.3 \pm 2.8$ & 0.385 \\
\hline
\end{tabular}

${ }^{*} p<0.15$

Data present as mean \pm SD 
Table 5 Outcome measures after biomechanical anti-pronation taping

\begin{tabular}{lllll}
\hline Variable & All Subjects $(n=74)$ & Success $(n=49)$ & Nonsuccess $(n=25)$ & $3.1 \pm 2.3$ \\
\hline First-step pain NRS & $3.0 \pm 2.5$ & $3.0 \pm 2.7$ & $-1.2 \pm 1.7$ & 0.924 \\
Change in first-step pain NRS & $-1.5 \pm 2.2$ & $-1.7 \pm 2.4$ & $3.3 \pm 1.6$ & 0.395 \\
Usual pain NRS & $3.1 \pm 2.0$ & $2.9 \pm 2.1$ & $-1.1 \pm 1.6$ & 0.438 \\
Change in usual pain NRS & $-1.8 \pm 1.9$ & $-2.1 \pm 2.0$ & $6.3 \pm 1.6$ & $0.023^{*}$ \\
PSFS & $6.3 \pm 1.8$ & $6.4 \pm 1.9$ & $1.8 \pm 1.8$ & 0.812 \\
Change in PSFS & $1.8 \pm 1.6$ & $1.8 \pm 1.5$ & $27.0 \pm 20.1$ & 0.975 \\
FFI & $24.6 \pm 19.8$ & $23.3 \pm 19.8$ & $-5.6 \pm 12.3$ & 0.462 \\
Change in FFI & $-9.7 \pm 14.8$ & $-11.9 \pm 15.6$ & $3.00 \pm 1.8$ & $0.082^{*}$ \\
GROC & $3.2 \pm 1.9$ & $3.4 \pm .0$ & & 0.456 \\
\hline
\end{tabular}

* $p<0.15$

NRS Numeric rating scale, PSFS Patient-specific functional scale, FFI Foot function index, GROC Global rating of changes

Acquisition of change score of each variable is by subtracting the baseline value from the posttest value of each outcome measure after taping

Data present as mean \pm SD

reduction of pain intensity by over 1.5 points after anti-pronation taping can become an objective indicator to subsequently prescribe foot orthoses.

The second significant predictor for positive outcome was the range of ankle plantarflexion > 54 degrees'. According to a previous study reporting the normative values of joint range of motion, the mean value of ankle plantarflexion was 56.5 degrees for general population [43]. Greater than normal ankle plantarflexion range implies excessive length of the ankle dorsiflexor muscles [44]. Excessive length of a muscle has been associated with over-stretch weakness, which indicates that elongated muscles appear to be less efficient in generating force $[45,46]$. The efficiency of an elongated tibialis anterior to eccentrically control foot pronation during walking and running could be affected [44]. Theoretically, elongation of tibialis anterior, associated with greater plantarflexion range, could increase the amount of navicular drop when weight bearing on the foot. Hence, greater plantarflexion range could contribute to excessive foot pronation [44]. The findings of our study provided a clinical implication that patients with PHP who had greater than normal range of ankle plantarflexion were more likely to benefit from the six-month foot orthosis intervention.

The strength of ankle plantarflexors on the symptomatic side equal to or stronger than that on the contralateral side was the third predictor of positive response found in the present study. The ankle plantarflexor strength has been considered as an essential factor contributing to the step length and walking velocity $[5,6]$. There were three potential roles of ankle plantarflexor in gait proposed in the previous study [6]: (1) to assist the trunk balance when weight-bearing on the foot, (2) to transfer the lower limb from the stance phase to the swing phase, and (3) to assist the human body moving forward. People

Table 6 Accuracy statistics (95\% confidence intervals) for potential predictors (pre-test rate of success 66\%)

\begin{tabular}{lllll}
\hline Variable & Sensitivity & Specificity & Positive likelihood ratio & Posttest probability \\
\hline Baseline pain $>4.5$ points & $0.59(0.44,0.73)$ & $0.48(0.28,0.69)$ & $1.14(0.73,1.77)$ & $69 \%(59,75 \%)$ \\
Forefoot varus $>10$ degrees & $0.69(0.55,0.82)$ & $0.36(0.18,0.57)$ & $1.08(0.77,1.54)$ & $68 \%(60,75 \%)$ \\
Ankle plantarflexion ROM $>54$ degrees & $0.55(0.40,0.69)$ & $0.60(0.39,0.79)$ & $1.38(0.80,2.37)$ & $73 \%(61,82 \%)$ \\
Hip internal rotation ROM < 39 degrees & $0.57(0.42,0.71)$ & $0.68(0.47,0.85)$ & $1.79(0.96,3.32)$ & $78 \%(65,87 \%)$ \\
Hip external rotation ROM > 45 degrees & $0.73(0.59,0.85)$ & $0.52(0.31,0.72)$ & $1.53(0.98,2.38)$ & $75 \%(66,82 \%)$ \\
$\begin{array}{l}\text { Ankle plantarflexors strength (the symptomatic } \\
\text { side } \geq \text { the contralateral side) }\end{array}$ & $0.69(0.55,0.82)$ & $0.68(0.47,0.85)$ & $2.17(1.19,3.95)$ & $81 \%(70,89 \%)$ \\
$\begin{array}{l}\text { Average pain intensity decreased by over } \\
\text { 1.5 points with taping }\end{array}$ & $0.69(0.55,0.82)$ & $0.68(0.47,0.85)$ & $2.17(1.19,3.95)$ & $81 \%(70,89 \%)$ \\
FFI score decreased by over 8 points with taping & $0.65(0.50,0.78)$ & $0.64(0.43,0.82)$ & $1.81(1.04,3.18)$ & $78 \%(67,86 \%)$ \\
\hline
\end{tabular}


Table 7 Prevalence of individual and grouped prognostic factors at each level

\begin{tabular}{lll}
\hline Variable & Success group $(n=49)$ & Nonsuccess group $(n=25)$ \\
\hline 5 & 3 & 0 \\
$4+$ & 17 & 1 \\
$3+$ & 42 & 5 \\
$2+$ & 48 & 17 \\
$1+$ & 49 & 23 \\
\hline
\end{tabular}

*Predictors: the average pain intensity decreased by over 1.5 points with taping, ankle plantarflexion ROM $>54$ degrees, the strength of ankle plantarflexors on the symptomatic side equal to or stronger than that on the contralateral side, hip internal rotation $\mathrm{ROM}<39$ degrees, and hip external rotation $\mathrm{ROM}>45$ degrees

who had weak ankle plantarflexor exhibited slower walking speed and shorter step length $[5,6]$, which significantly associated with lower extremity function. The current result indicated that patients with PHP who had the same or stronger ankle plantarflexors on the symptomatic side still retained appropriate foot function and, therefore had a higher chance to respond to the foot orthosis treatment. This study result also implies that patients with PHP whose ankle plantarflexors strength was less than that of the other side should be recommended to perform strengthening exercises. Rathleff et al. conducted a clinical trial and found that a 3mouth single heel raising training program significantly decreased pain and improved foot function in patients with PHP [47].

The last 2 significant predictors identified from the current study were both pertaining to the hip mobility. One predictor was 'the range of hip internal rotation < 39 degrees', and the other was 'the range of hip external rotation $>45$ degrees'. This clinical presentation with increased external rotation and decreased internal rotation ranges of motion at the hip was found in a study to be a risk factor associated with medial tibial stress syndrome [48]. A possible explanation can be postulated that these changes in hip rotation range of motion caused people to walk with an out-toeing gait which might increase the medial rotation loading on tibia and result in excessive foot pronation. Excessive out-toeing leads to a number of lower extremity problems associated with abnormal foot pronation, such as plantar fasciitis [4, 49] and medial tibial stress syndrome [44, 50-52]. The use of foot orthoses could not only control the foot overpronation but also exert an influence on the proximal segments of the lower extremity. From the observation in this study, patients with PHP who exhibited these clinical characteristics (increased hip external rotation range and decreased hip internal rotation range) had a higher chance of achieving positive outcome with customized foot orthoses.

There were several limitations in our study. Firstly, because of the use of a single group design, we are unable to infer the effectiveness of foot orthoses for patients with PHP. The second limitation was that the current clinical predictors may not be generalized to the whole population because women accounted for $77 \%$ in this study population. More importantly, after identifying the preliminary clinical predictors, these significant predictors must be validated by welldesigned randomized controlled trials in future.

\section{Conclusion}

This study identified five significant predictors that determined which patients with PHP would respond positively to customized foot orthoses. These predictors for the effect of customized foot orthosis in patients with PHP are related to several physical measures of a lower extremity. The clinical prediction rule derived from this study can be used to screen and select patients with PHP for foot orthosis intervention. Moreover, we verified the concept that if a patient had a positive 'treatment direction test' (i.e. improvement on pain after receiving anti-pronation taping), we could assume this patient would benefit from the foot orthoses intervention. From the current study results, a reduction of pain intensity by over 1.5

Table 8 Accuracy statistics for 5 levels of the clinical predictors* (95\% confidence intervals)

\begin{tabular}{lllll}
\hline Variable & Sensitivity & Specificity & Positive likelihood ratio & Posttest probability \\
\hline 5 & $0.06(0.01,0.17)$ & $1.00(0.86,1.00)$ & inf (inf, inf) & $100 \%(100,100 \%)$ \\
$4+$ & $0.35(0.22,0.50)$ & $0.96(0.80,1.00)$ & $8.67(1.22,61.48)$ & $94 \%(71,99 \%)$ \\
$3+$ & $0.86(0.73,0.94)$ & $0.80(0.59,0.93)$ & $4.29(1.94,9.46)$ & $89 \%(79,95 \%)$ \\
$2+$ & $0.98(0.89,1.00)$ & $0.32(0.15,0.54)$ & $1.44(1.10,1.89)$ & $74 \%(68,79 \%)$ \\
$1+$ & $1.00(0.93,1.00)$ & $0.08(0.01,0.26)$ & $1.09(0.97,1.22)$ & $68 \%(65,71 \%)$ \\
\hline
\end{tabular}

inf: infinity

*Predictors: the average pain intensity decreased by over 1.5 points with taping, ankle plantarflexion ROM $>54$ degrees, the strength of ankle plantarflexors on the symptomatic side equal to or stronger than that on the contralateral side, hip internal rotation ROM $<39$ degrees, and hip external rotation ROM $>45$ degrees 
points after application of an anti-pronation taping is an objective indicator of favorable outcome following foot orthoses treatment. However, since there was no control group in the current study, it is inappropriate to draw conclusions about the effectiveness of the foot orthoses treatment.

\section{Acknowledgements}

We would like to thank Dr. Shun-Hua Wei for providing assistance for data collection. We also thank Mr. Mark Comerford for giving us constructive advice on our study.

\section{Authors' contributions}

FLW designed the research, collected the data, and wrote the manuscript; YFS contributed in theory development, data interpretation and manuscript editing; SHL contributed in subject recruitment and writing the manuscript; HJL contributed in data analysis and interpretation; WTW conceived the presented idea, supervised the findings of this work, and wrote the manuscript. All authors have read and approved the manuscript.

\section{Funding}

This study was supported by a grant from the Ministry of Education, Aim for the Top University Plan and National Yang-Ming University. The funders had no role in study design, data collecting and analysis, decision to publish, or preparing the manuscript.

\section{Availability of data and materials}

The datasets used in the present study may be available from the corresponding author on reasonable requests.

\section{Ethics approval and consent to participate}

The study has been approved by the Institutional Research Board at Taipei Veterans General Hospital. Written informed consent was obtained from all participants included in the study (2013-01-026B).

\section{Consent for publication}

Not applicable.

\section{Competing interests}

The authors declare that they have no competing interests.

\section{Author details}

'Department of Physical Therapy and Assistive Technology, National Yang-Ming University, No.155, Sec.2, Linong Street, Taipei 112, Taiwan, Republic of China. ${ }^{2}$ Department of Physical Medicine and Rehabilitation, Taipei Veterans General Hospital, Taipei, Taiwan.

Received: 28 December 2018 Accepted: 21 May 2019

Published online: 31 May 2019

\section{References}

1. Rome K, Howe T, Haslock I. Risk factors associated with the development of plantar heel pain in athletes. Foot. 2001;11(3):119-25

2. Taunton JE, Ryan MB, Clement DB, McKenzie DC, Lloyd-Smith DR, Zumbo $\mathrm{BD}$. A retrospective case-control analysis of 2002 running injuries. $\mathrm{Br} \mathrm{J}$ Sports Med. 2002;36(2):95-101.

3. Rome K. Anthropometric and biomechanical risk factors in the development of plantar heel pain —a review of the literature. Phys Ther Rev. 1997;2(3): 123-34.

4. Martin RL, Davenport TE, Reischl SF, McPoil TG, Matheson JW, Wukich DK, McDonough CM, American Physical Therapy Association. Heel pain-plantar fasciitis: revision 2014. J Orthop Sports Phys Ther. 2014;44(11):A1-33.

5. Wearing SC, Smeathers JE, Sullivan PM, Yates B, Urry SR, Dubois P. Plantar fasciitis: are pain and fascial thickness associated with arch shape and loading? Phys Ther. 2007:87(8):1002-8

6. Irving DB, Cook JL, Young MA, Menz HB. Obesity and pronated foot type may increase the risk of chronic plantar heel pain: a matched case-control study. BMC Musculoskelet Disord. 2007:8:41.
7. Lopes AD, Hespanhol Junior LC, Yeung SS, Costa LO. What are the main running-related musculoskeletal injuries? A Systematic Review Sports Med. 2012:42(10):891-905

8. Sobhani S, Dekker R, Postema K, Dijkstra PU. Epidemiology of ankle and foot overuse injuries in sports: a systematic review. Scand J Med Sci Sports. 2013; 23(6):669-86.

9. Di Caprio F, Buda R, Mosca M, Calabro A, Giannini S. Foot and lower limb diseases in runners: assessment of risk factors. J Sports Sci Med. 2010;9(4): $587-96$

10. Cheung RT, Chung RC, Ng GY. Efficacies of different external controls for excessive foot pronation: a meta-analysis. Br J Sports Med. 2011; 45(9):743-51.

11. Lee SY, McKeon P, Hertel J. Does the use of orthoses improve self-reported pain and function measures in patients with plantar fasciitis? A metaanalysis Phys Ther Sport. 2009:10(1):12-8.

12. Hume P, Hopkins W, Rome K, Maulder P, Coyle G, Nigg B. Effectiveness of foot orthoses for treatment and prevention of lower limb injuries : a review. Sports Med. 2008;38(9):759-79.

13. Hawke F, Burns J, Radford JA, du Toit V. Custom-made foot orthoses for the treatment of foot pain. Cochrane Database Syst Rev. 2008;16(3): CD006801.

14. Smith M, Brooker S, Vicenzino B, McPoil T. Use of anti-pronation taping to assess suitability of orthotic prescription: case report. Aust J Physiother. 2004:50(2):111-3.

15. Vicenzino B. Foot orthotics in the treatment of lower limb conditions: a musculoskeletal physiotherapy perspective. Man Ther 2004;9(4):185-96.

16. Meier K, McPoil TG, Cornwall MW, Lyle T. Use of antipronation taping to determine foot orthoses prescription: a case series. Res Sports Med. 2008; 16(4):257-71.

17. Puentedura EJ, Cleland JA, Landers MR, Mintken PE, Louw A, Fernandez-de-Las-Penas C. Development of a clinical prediction rule to identify patients with neck pain likely to benefit from thrust joint manipulation to the cervical spine. J Orthop Sports Phys Ther. 2012;42(7):577-92

18. Flynn T, Fritz J, Whitman J, Wainner R, Magel J, Rendeiro D, Butler B, Garber M, Allison S. A clinical prediction rule for classifying patients with low back pain who demonstrate short-term improvement with spinal manipulation. Spine (Phila Pa 1976). 2002;27(24):2835-43.

19. Vicenzino B, Collins N, Cleland J, McPoil T. A clinical prediction rule for identifying patients with patellofemoral pain who are likely to benefit from foot orthoses: a preliminary determination. Br J Sports Med. 2010; 44(12):862-6.

20. Hawker GA, Mian S, Kendzerska T, French M. Measures of adult pain: Visual Analog Scale for Pain (VAS Pain), Numeric Rating Scale for Pain (NRS Pain), McGill Pain Questionnaire (MPQ), Short-Form McGill Pain Questionnaire (SF-MPQ), Chronic Pain Grade Scale (CPGS), Short Form36 Bodily Pain Scale (SF-36 BPS), and Measure of Intermittent and Constant Osteoarthritis Pain (ICOAP). Arthritis Care Res. (Hoboken) 2011; 63 Suppl 11:S240-52

21. Wu SH, Liang HW, Hou WH. Reliability and validity of the Taiwan Chinese version of the foot function index. J Formos Med Assoc. 2008; 107(2):111-8.

22. Horn KK, Jennings S, Richardson G, Vliet DV, Hefford C, Abbott JH. The patient-specific functional scale: psychometrics, clinimetrics, and application as a clinical outcome measure. J Orthop Sports Phys Ther. 2012;42(1):30-42.

23. Landorf KB, Radford JA. Minimal important difference: values for the foot health status questionnaire, foot function index and visual analogue scale. Foot. 2008:18(1):15-9.

24. Medina McKeon JM, Hertel J. Sex differences and representative values for 6 lower extremity alignment measures. J Athl Train. 2009; 44(3):249-55.

25. Elveru RA, Rothstein JM, Lamb RL, Riddle DL. Methods for taking subtalar joint measurements. A clinical report. Phys Ther. 1988;68(5):678-82.

26. Lamm BM, Mendicino RW, Catanzariti AR, Hillstrom HJ. Static rearfoot alignment: a comparison of clinical and radiographic measures. J Am Podiatr Med Assoc. 2005;95(1):26-33.

27. Spink MJ, Fotoohabadi MR, Menz HB. Foot and ankle strength assessment using hand-held dynamometry: reliability and age-related differences. Gerontology. 2010;56(6):525-32. 
28. Kelln BM, McKeon PO, Gontkof LM, Hertel J. Hand-held dynamometry: reliability of lower extremity muscle testing in healthy, physically active,young adults. J Sport Rehabil 2008;17(2):160-170.

29. Kwon OY, Tuttle LJ, Commean PK, Mueller MJ. Reliability and validity of measures of hammer toe deformity angle and tibial torsion. Foot. (Edinb) 2009;19(3):149-55.

30. Stuberg W, Temme J, Kaplan P, Clarke A, Fuchs R. Measurement of tibial torsion and thigh-foot angle using goniometry and computed tomography. Clin Orthop Relat Res. 1991;272:208-12.

31. Nilsson MK, Friis R, Michaelsen MS, Jakobsen PA, Nielsen RO. Classification of the height and flexibility of the medial longitudinal arch of the foot. J Foot Ankle Res. 2012;5:3.

32. Jarvis HL, Nester CJ, Jones RK, Williams A, Bowden PD. Inter-assessor reliability of practice based biomechanical assessment of the foot and ankle. J Foot Ankle Res. 2012;5:14

33. Neto T, Jacobsohn L, Carita Al, Oliveira R. Reliability of the Active-KneeExtension and Straight-Leg-Raise Tests in Subjects With Flexibility Deficits. J Sport Rehabil. 2015;Technical Notes 17:2014-0220.

34. Clapis PA, Davis SM, Davis RO. Reliability of inclinometer and goniometric measurements of hip extension flexibility using the modified Thomas test. Physiother Theory Pract. 2008;24(2):135-41.

35. Reese NB, Bandy WD. Use of an inclinometer to measure flexibility of the iliotibial band using the Ober test and the modified Ober test: differences in magnitude and reliability of measurements. J Orthop Sports Phys Ther. 2003:33(6):326-30.

36. Redmond AC, Crosbie J, Ouvrier RA. Development and validation of a novel rating system for scoring standing foot posture: the Foot Posture Index. Clin Biomech. (Bristol, Avon) 2006;21(1):89-98.

37. Landorf KB, Radford JA, Keenan AM, Redmond AC. Effectiveness of low-dye taping for the short-term management of plantar fasciitis. J Am Podiatr Med Assoc. 2005;95(6):525-30.

38. Hyland MR, Webber-Gaffney A, Cohen L, Lichtman PT. Randomized controlled trial of calcaneal taping, sham taping, and plantar fascia stretching for the short-term management of plantar heel pain. J Orthop Sports Phys Ther. 2006;36(6):364-71.

39. Jaeschke R, Singer J, Guyatt GH. Measurement of health status. Ascertaining the minimal clinically important difference. Control Clin Trials. 1989;10(4): 407-15.

40. Kamper SJ, Maher CG, Mackay G. Global rating of change scales: a review of strengths and weaknesses and considerations for design. J Man Manip Ther. 2009;17(3):163-70.

41. Peduzzi P, Concato J, Kemper E, Holford TR, Feinstein AR. A simulation study of the number of events per variable in logistic regression analysis. J Clin Epidemiol. 1996;49(12):1373-9.

42. Harrell FJ, Lee KL, Mark DB. Multivariable prognostic models: issues in developing models, evaluating assumptions and adequacy, and measuring and reducing errors. Stat Med. 1996;15:361-87.

43. Soucie JM, Wang C, Forsyth A, Funk S, Denny M, Roach KE, Boone D. Hemophilia treatment center $\mathrm{N}$. range of motion measurements: reference values and a database for comparison studies. Haemophilia. 2011;17(3):500-7.

44. Yates $\mathrm{B}$, White $\mathrm{S}$. The incidence and risk factors in the development of medial tibial stress syndrome among naval recruits. Am J Sports Med. 2004; 32(3):772-80.

45. Sahrmann S. Diagnosis and treatment of movement impairment syndromes: Elsevier health sciences; 2002.

46. Comerford MJ, Mottram SL. Movement and stability dysfunction-contemporary developments. Man Ther. 2001;6(1):15-26.

47. Rathleff MS, Molgaard CM, Fredberg U, Kaalund S, Andersen KB, Jensen T, Aaskov S, Olesen JL. High-load strength training improves outcome in patients with plantar fasciitis: a randomized controlled trial with 12-month follow-up. Scand J Med Sci Sports. 2015;25(3):e292-300.

48. Moen MH, Bongers T, Bakker EW, Zimmermann WO, Weir A, Tol JL, Backx FJ. Risk factors and prognostic indicators for medial tibial stress syndrome. Scand J Med Sci Sports. 2012;22(1):34-9.

49. Lee MS, Vanore JV, Thomas JL, Catanzariti AR, Kogler G, Kravitz SR, Miller SJ, Gassen SC. Clinical practice guideline adult flatfoot P. diagnosis and treatment of adult flatfoot. J Foot Ankle Surg. 2005:44(2): 78-113.

50. Hamstra-Wright KL, Bliven KC, Bay C. Risk factors for medial tibial stress syndrome in physically active individuals such as runners and military personnel: a systematic review and meta-analysis. Br J Sports Med. 2015; 49(6):362-9.

51. Newman P, Witchalls J, Waddington G, Adams R. Risk factors associated with medial tibial stress syndrome in runners: a systematic review and meta-analysis. Open Access J Sports Med. 2013;4:229-41.

52. Winkelmann ZK, Anderson D, Games KE, Eberman LE. Risk factors for medial Tibial stress syndrome in active individuals: an evidence-based review. J Ath Train. 2016;51(12):1049-52.

\section{Publisher's Note}

Springer Nature remains neutral with regard to jurisdictional claims in published maps and institutional affiliations.

\section{Ready to submit your research? Choose BMC and benefit from:}

- fast, convenient online submission

- thorough peer review by experienced researchers in your field

- rapid publication on acceptance

- support for research data, including large and complex data types

- gold Open Access which fosters wider collaboration and increased citations

- maximum visibility for your research: over $100 \mathrm{M}$ website views per year

At BMC, research is always in progress.

Learn more biomedcentral.com/submissions 